\title{
Biosynthesis of colloidal Copper Oxide Nanoparticles using Manilkara hexandra (Roxb.) Dubard leaf extract and its Physicochemical Characterization and Pharmaceutical Evaluation
}

\author{
A Antony Lawrence ${ }^{1 *}, J_{\text {Thomas Joseph Prakash }}{ }^{*}$ \\ ${ }^{1,2}$ Department of Physics, Government Arts College (Affiliated to Bharathidasan University), Trichy-620022, India \\ *Corresponding Author: armyjpr1@yahoo.co.in, Tel.: +91-9842470521
}

Available online at: www.isroset.org

Received: 04/Dec/2018, Accepted: 18/Dec/2018, Online: 31/Dec/2018

\begin{abstract}
In the present investigation, plant mediated bio-synthesis of copper oxide nanoparticles is synthesized using Manilkara hexandra leaf extract and were further characterized using Fourier transform infrared spectroscopy (Presence of biomolecules), UV-vis spectroscopy (250-300 nm), Field electron scanning electron microscope (30 to $60 \mathrm{~nm}$ ), Energy dispersive x-ray analysis ( $\mathrm{Cu}, \mathrm{O}$ elements), X-ray diffraction analysis (face-centered cubic structure ), Particle size analyser $(343 \mathrm{~nm})$, Zeta potential $(-9.50 \mathrm{mV})$. The Thermogravimetry/Differential Thermal Analysis and Differential scanning calorimetry is also examined to find the stability of materials. This confirms that copper oxide nanoparticles are well formed and synthesized. They are further tested with anti-microbial assays and antioxidant evaluation (DPPH method in-vitro) these reports show high estimation. This confirms that the copper oxide nanoparticles can be produced in large scale and can be implied for prevention of food, crops and drug delivery system.
\end{abstract}

Keywords- Manilkara hexandra, Copper oxide nanoparticles, Anti-microbial assays, DPPH method.

\section{INTRODUCTION}

Traditionally, plants play a major role in the drug in the human. The presence of phytochemicals present in a medicinal plant is useful for curing and healing human diseases [1]. Nanomaterials have a wide view of the application in human life and its environment. Some knowledge of nanoscale fabrication was about 5000 years old Indian system of medicine, Ayurveda for medicinal purposes [2]. The ancient book Ras-Ratnakar by Nagarjuna (50 B.C.) clearly describes the process of formation of Bhasma which is a special kind of Ayurvedic medicine. A combination of traditional method and new scientific method formulate a new approach to metal nanoparticles. The physical and chemical method can produce pure and well-defined nanoparticles, it is quite expensive and dangerous to the environment and not eco-friendly [3]. Among various methods, plantmediated nanoparticles have a high impact because of its cost-effective, environmentally friendly and safe for human therapeutic use [4]. It is a bottom-up approach. The novel nanoparticles were synthesized by researchers with continuous efforts for industrial and technological advancements. The metal nanoparticles $(\mathrm{Cu}, \mathrm{Ag}, \mathrm{Au} \& \mathrm{Pt})$ have the high impact of microorganisms and is been reported [5-7]. Among various metal CuNPs has versatile applications such as optical, catalytic, antibacterial and antifungal [8-9]. It is also used in gas sensors, dye-sensitized solar cells (DSSCS), paints, filters, plastics and textiles [10-12]. Etc.

The aim of the present work is to synthesize copper oxide nanoparticles using Manilkara hexandra leaf extract. The extract act as reducing and stabilizing agent. This green synthesized copper oxide nanoparticles are characterized by various methods such as UV, FT-IR, FE-SEM, EDAX, XRD, DLS, Zeta Potential, TG/DTA and DSC. Silver nanoparticles was tested against antimicrobial and antioxidant assay. This shows a high zone of inhibition and good antioxidant property.

\section{MATERIALS AND METHODS}

\subsection{Chemicals and scientific name of plants}

All chemicals and solvent of AR grade were purchased from Sigma Aldrich, India. The Manilkara hexandra (Roxb.) Dubard leaves were collected from Jayakondam district, Tamil Nadu. Identified in Rapinet herbarium, St. Joseph College, Trichy, India. (Voucher No: AAL 001 and Figure 1). 


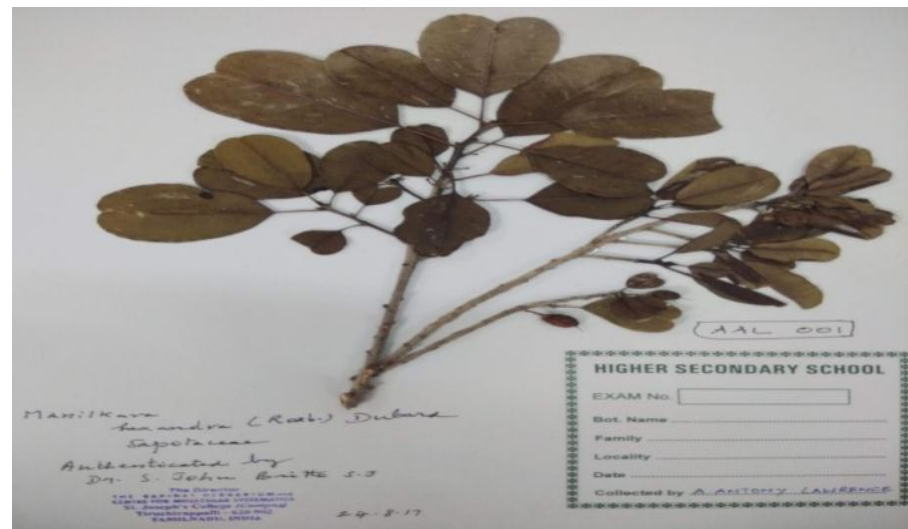

Figure 1. Manilkara hexandra (Roxb.) Dubard identified by Rapinet herbarium.

\subsection{Scientific name and medicinal properties of plant}

The botanical name of the plant is Manilkara hexandra (Roxb.) Dubard belong to Sapotaceae family, Genus - Manilkara, Species - Manilkara hexandra, in Tamil it is called as Ulakkaippaalai or Kanuppaalai. The Manilkara hexandra grow in wild conditions and has various medicinal values such as anorexia, loss of consciousness, dyspepsia, astringent, odontopathy, burning sensation, leprosy etc [13].

\subsection{Preparation of leaf extract}

The leaves were collected and washed in flowing water and then again washed with de-ionized water and dried in the room for two weeks. The dried leaves were grained using pestle mortar into a fine powder. Ten grams of leaf powder were weighted using an electronic balancing scale and soaked in $100 \mathrm{ml}$ of de-ionized water of $30 \mathrm{mins}$, then heated at $60^{\circ} \mathrm{C}$ for 10 minutes in a heating mantle. The extracts were then filtered using What man No.1 filter paper and stored at $5^{\circ} \mathrm{C}$ for future use.

\subsection{Phytochemical screening}

The stored extract was analyzed qualitatively to identify phytochemicals such as alkaloids, flavonoids, terpenoid, saponin, tannin, amino acid, protein, carbohydrates, emodins, quinone, resin, phlobatannin, coumarins, anthraquinone, oils and fat, gum, anthocyanin, glycosides, steroids, and xanthoprotein [14].

\subsection{Preparation of copper sulfate solution}

1.248 grams of copper sulfate pentahydrate $\left(\mathrm{CuSO}_{4} \cdot 5 \mathrm{H}_{2} \mathrm{O}\right)$ were weighted and mixed with $1000 \mathrm{ml}$ of de-ionized water and made for $5 \mathrm{mM}$ copper sulfate solution shown in Figure 2.

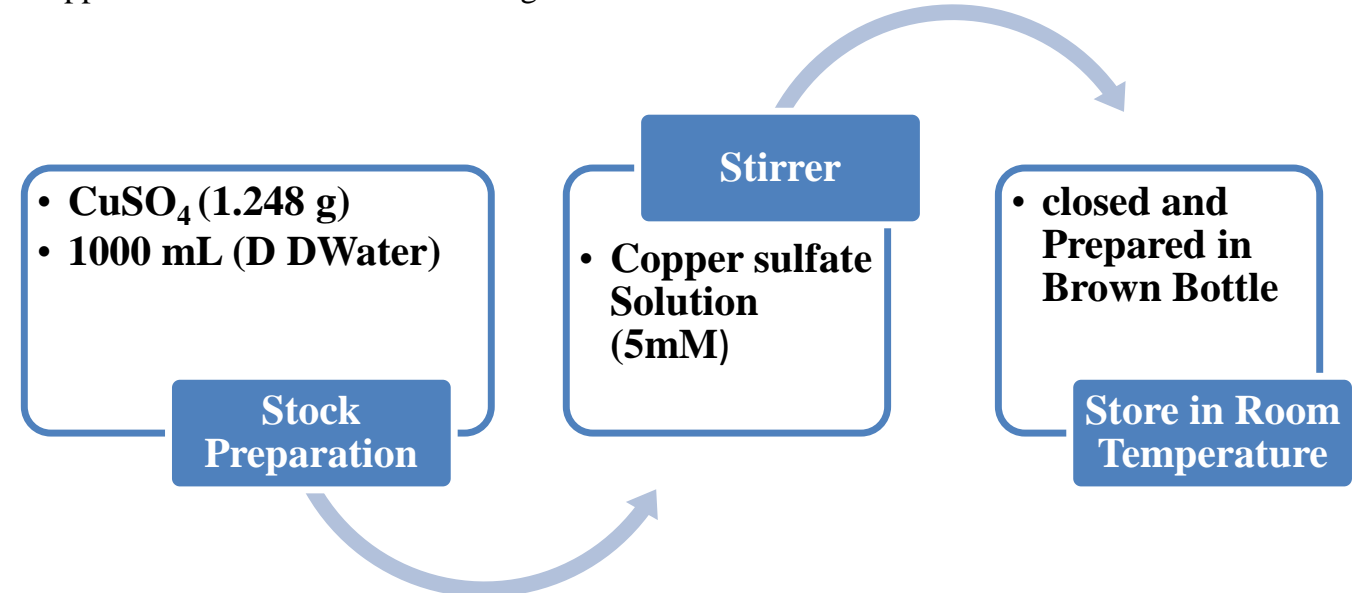

Figure 2. Preparation of Copper Sulfate solution (5mM).

\subsection{Biosynthesis of copper oxide nanoparticles}

The copper oxide nanoparticles were synthesized using $90 \mathrm{ml}$ of copper sulfate solution mixed with $10 \mathrm{ml}$ of Manilkara hexandra leaf extracts. The change of color is observed, which indicate the presence of copper oxide nanoparticles. MHL-CuO 
NPs were collected using centrifuged techniques (Remi 12C) at 12,000 rpm. Then the particles are collected, dried and purified using alcohol and it was powdered.

\subsection{Characterization}

These copper oxide nanoparticles were characterized by using various instruments such as the UV-Visible spectrometer (U2910 Hitachi) in the wavelength range $200-1100 \mathrm{~nm}$. The functional group was identified by FTIR (IRAffinity-1S Shimadzu) wavelength range from 4000 to $400 \mathrm{~cm}^{-1}$. The morphological studies and elemental composition of MHL-CuO NPs were studied using FE-SEM and EDX (FEI QUANTA-250 FEG). The crystallinity of MHL-CuO NPs was analyzed by X-ray diffraction (X' Pert Pro-P Analytic). The size distribution and Zeta Potential of MHL-CuO NPs was also analyzed using the particle size analyzer (Zetasizer 7.11, Malvern, Instruments Ltd). The MHL-CuO NPs thermally examined by Thermogravimetry/Differential Thermal Analysis (TG/DTA) model number ( SDT Q600 V20.9 Build 20) and Differential scanning calorimetry (DSC) model number ( NETZSCH DSC 214 Polyma).

\subsection{Antimicrobial assays}

\subsubsection{Collection of bacterial strains and antibacterial assays}

Four diverse human pathogenic microbes are inspected in the trial. Two-gram +ve bacterial strains Staphylococcus aureus (MTCC 25923) and Bacillus subtilis (MTCC 2451). Two gram -ve bacterial strains Escherichia coli (MTCC 25922) and Pseudomonas aeruginosa (MTCC 27853). These strains secured from microbial sort culture and gathered (MTCC) at Chandigarh, India. Every one of these strains was developed at $37^{\circ} \mathrm{C}$ and kept up on supplement agar (Difco, USA) incline at for $4^{\circ} \mathrm{C}$. The antibacterial potential for MHL-CuO NPs, Manilkara hexandra leaf extract, Copper sulfate solution $(5 \mathrm{mM})$, the standard was analyzed utilizing disc diffusion method. The muller hintor agar was set up in Petri dishes $(60 \mathrm{~mm})$ and

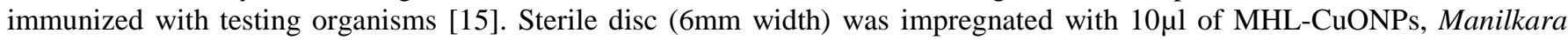
hexandra leaf extract, Copper sulfate solution, Amoxicillin. The sterile circle put on the top layer of the agar plates. The dishes are then brooded for $24 \mathrm{~h}$ at $37^{\circ} \mathrm{C}$ and the zone of inhibition is recorded. Amoxicillin is utilized as the standard for an antibiotic.

\subsubsection{Collection of fungal strains and antifungal assays}

Two distinctive parasitic strains Aspergillus flavus (MTCC-3396) and Aspergillus Niger (MTCC-227) were gained from National substance laboratory (NCL), Pune, Maharashtra, India. It is vaccinated independently in Sabouraud's dextrose stock for $6 \mathrm{~h}$ and is checked to give roughly $10^{5} \mathrm{CFU} / \mathrm{ml}$. The Antifungal movement is dissected for MHL-CuO NPs, Manilkara hexandra leaf extract, Copper sulfate solution $(5 \mathrm{mM})$, standard. The Sabouraud's dextrose agar is set up in Petri dishes $(60 \mathrm{~mm})$ and immunized with strains. The sterile disc $(6 \mathrm{~mm})$ was impregnated with $10 \mu \mathrm{l}$ of MHL-CuO NPs, Manilkara hexandra leaf extract, Copper sulfate, and fluconazole. The dishes were brooded for $24 \mathrm{~h}$ at $37^{\circ} \mathrm{C}$ and the zone of restraint is recorded. Fluconazole is utilized as the standard for anti-infective.

\subsection{Antioxidant assays (in-vitro DPPH method)}

The 2, 2-diphenyl-2- picrylhydrazyl (DPPH) is used for examining free radical scavenging activity. DPPH radicals $(0.2 \mathrm{mM})$ are prepared in methanol solution. MHL-CuO NPs $(20-100 \mu \mathrm{g} / \mathrm{ml})$ in water mixed with one $\mathrm{ml}$ of prepared DPPH solution in a test tube. It is shaken vigorously and kept in a dark room for $30 \mathrm{~min}$ after absorbance is measured. Similarly, ascorbic acid is used as standard. After measuring the IC ${ }_{50}$ value is calculated [16].

The scavenging ability is calculated using formula.

$\%$ of inhibition $=100 \times\left(\frac{A-B}{A}\right)$

Where, I (\%) is inhibition percentage

A- Absorbance of control reaction

B- Sample absorbance of test compound.

\section{RESULT AND DISCUSSION}

The phytochemical screening of Manilkara hexandra aqueous leaf extract revealed the presence of alkaloid, flavonoids, terpenoids, amino acid, protein, quinone, anthraquinone, saponin, resin, carbohydrates, steroids, tannin, phlobatannin, gum \& mucilage, glycosides, and xanthoprotein. However, Manilkara hexandra aqueous leaf extract shows the negative answer for phytochemicals such as anthocyanin, emodins, fixed oils \& fats and coumarins. The medicinal behaviors depend on the 
phytochemicals present in the plant. In recent centuries, green synthesis of metal nanoparticles plays a major role in research due to its boundless application [17].

\subsection{Characterization of Copper oxide nanoparticles}

Formation of copper oxide nanoparticles is easily recognized by the change of color of the solution shown in Figure 3.

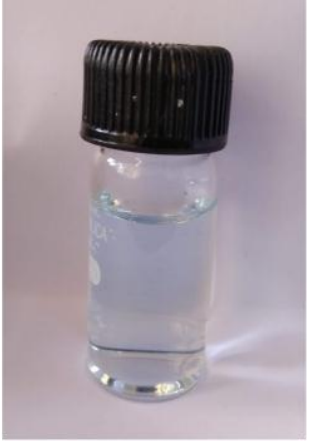

$\underset{(5 \mathrm{mM})}{\mathrm{CuSO}_{4} .5 \mathrm{H}_{2} \mathrm{O}}$
$\quad$

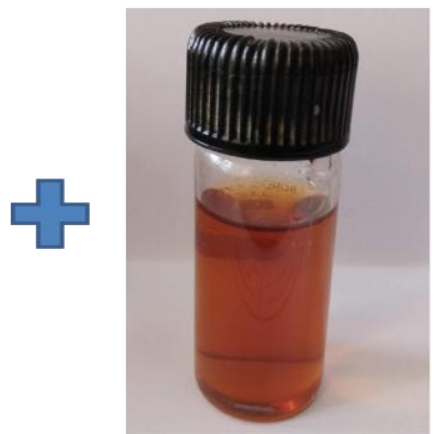

Leaf Extract

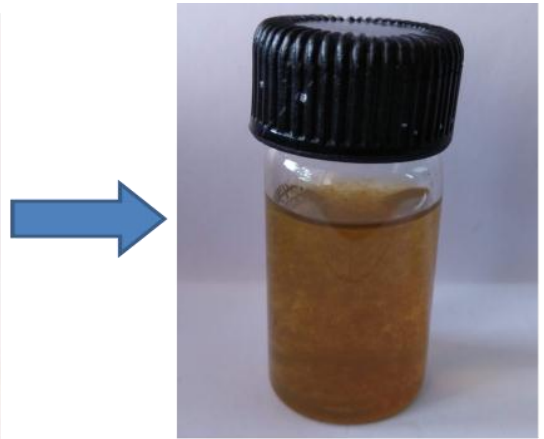

Copper oxide Nanoparticles

Figure 3. $\mathrm{CuSO}_{4} .5 \mathrm{H}_{2} \mathrm{O}(5 \mathrm{mM})$ mixed with leaf extract gives Copper oxide nanoparticles $(\mathrm{CuO} N \mathrm{NP})$.

The Manilkara hexandra leaf extract added with $5 \mathrm{mM}$ of cupric sulfate solution start the change in color reaches to dark brown after incubation for 48 hours after the color of the solution is been unchanged. The UV-vis spectra clearly project a strong absorbance between 250-300 $\mathrm{nm}$. This suggests the formation of copper oxide nanoparticles as in Figure 4. This SPR absorption initiates the reflection of the size and shape of nanoparticles [18].

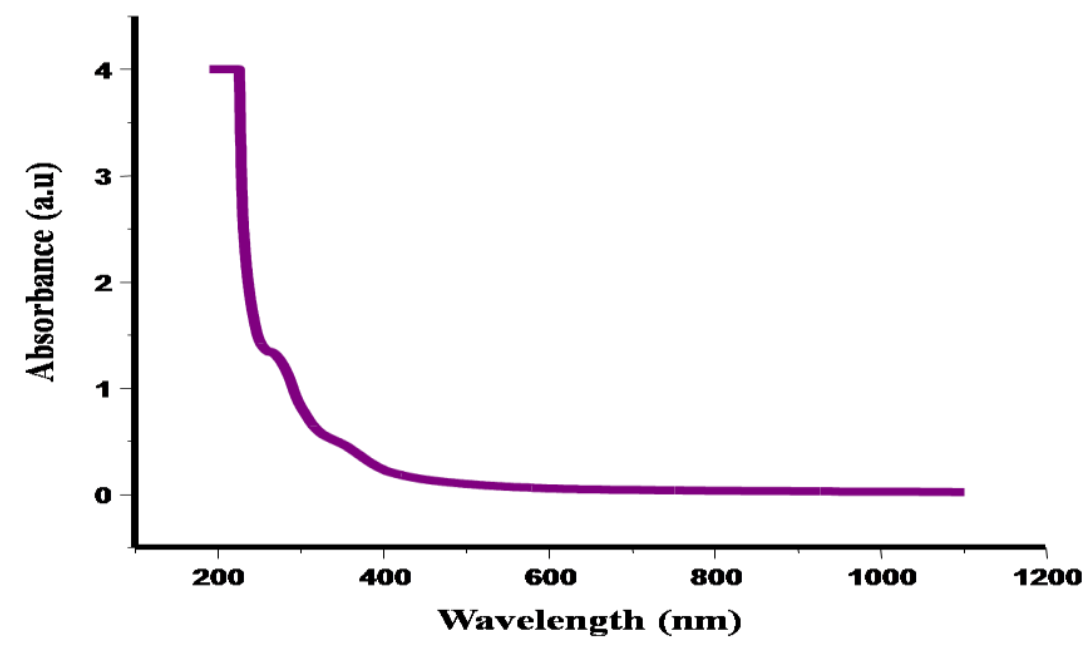

Figure 4. UV-vis spectroscopy indicating the synthesis of MHL-CuO NPs

Figure 5a shows the FTIR spectrum was observed for Manilkara hexandra aqueous leaf extract $3437 \mathrm{~cm}^{-1}$ (-OH group),1638 $\mathrm{cm}^{-1}$ ( $\mathrm{C}=\mathrm{C}$ of aromatic ring overlapped with the carbonyl group), $1384 \mathrm{~cm}^{-1}\left(\mathrm{NO}_{3}^{-}\right.$group), $1069 \mathrm{~cm}^{-1}$ (C-N stretching of amines) and $660 \mathrm{~cm}^{-1}\left(\mathrm{C}-\mathrm{H}\right.$ stretching). The disappearance of $1452 \mathrm{~cm}^{-1}$ peak and the relative shift of copper oxide nanoparticles are observed at $3437 \mathrm{~cm}^{-1}$ to $3447 \mathrm{~cm}^{-1}, 2075 \mathrm{~cm}^{-1}$ to $2076 \mathrm{~cm}^{-1}, 1638 \mathrm{~cm}^{-1}$ to $1637 \mathrm{~cm}^{-1}, 1069 \mathrm{~cm}^{-1}$ to $1116 \mathrm{~cm}^{-1}$ and $660 \mathrm{~cm}^{-1}$ to $675 \mathrm{~cm}^{-1}$. This clearly projects that oxidized polyphenols capped the surface of copper oxide nanoparticles. The mode of vibration for $\mathrm{CuO}$ nanoparticles range from $500 \mathrm{~cm}^{-1}$ to $700 \mathrm{~cm}^{-1}$. The major peak $675 \mathrm{~cm}^{-1}$ were observed to be $\mathrm{CuO}$ stretching as in Figure $5 b$. 


\section{$\mathbf{a}$}

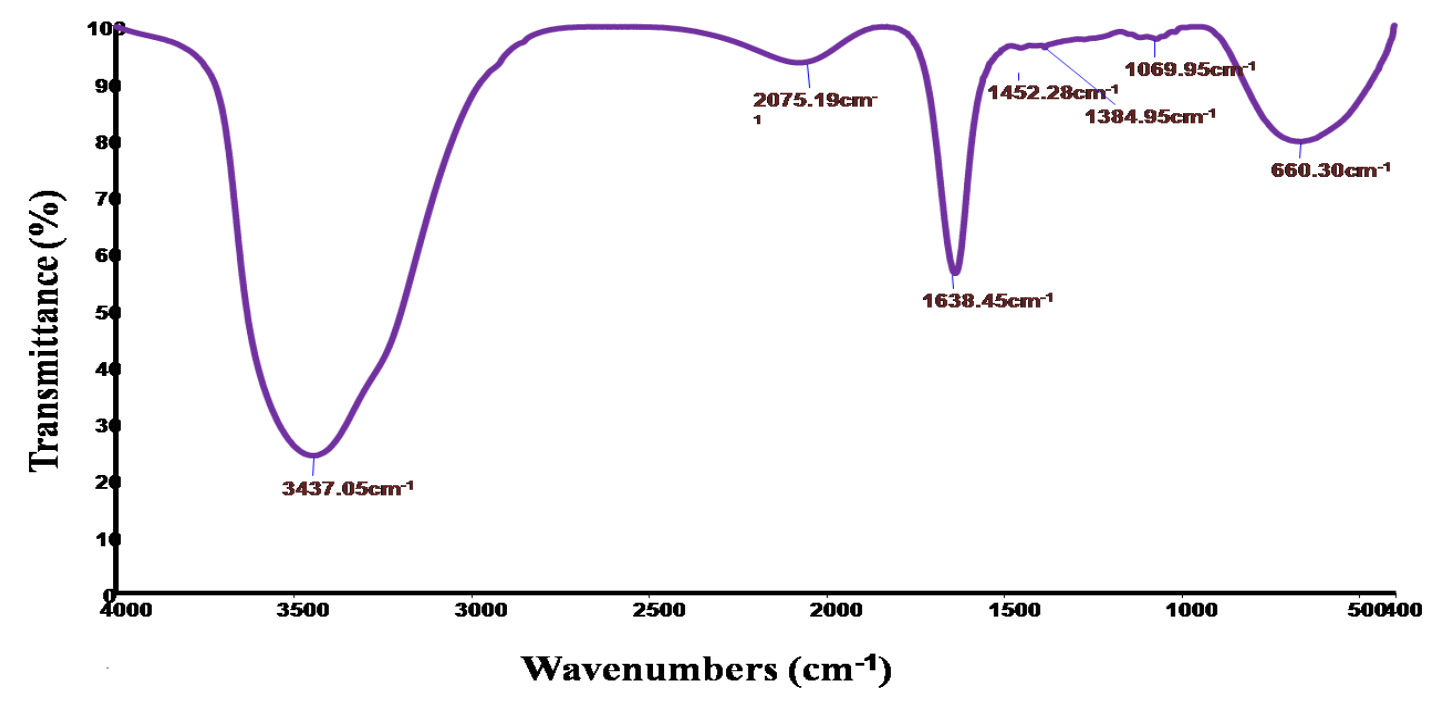

b

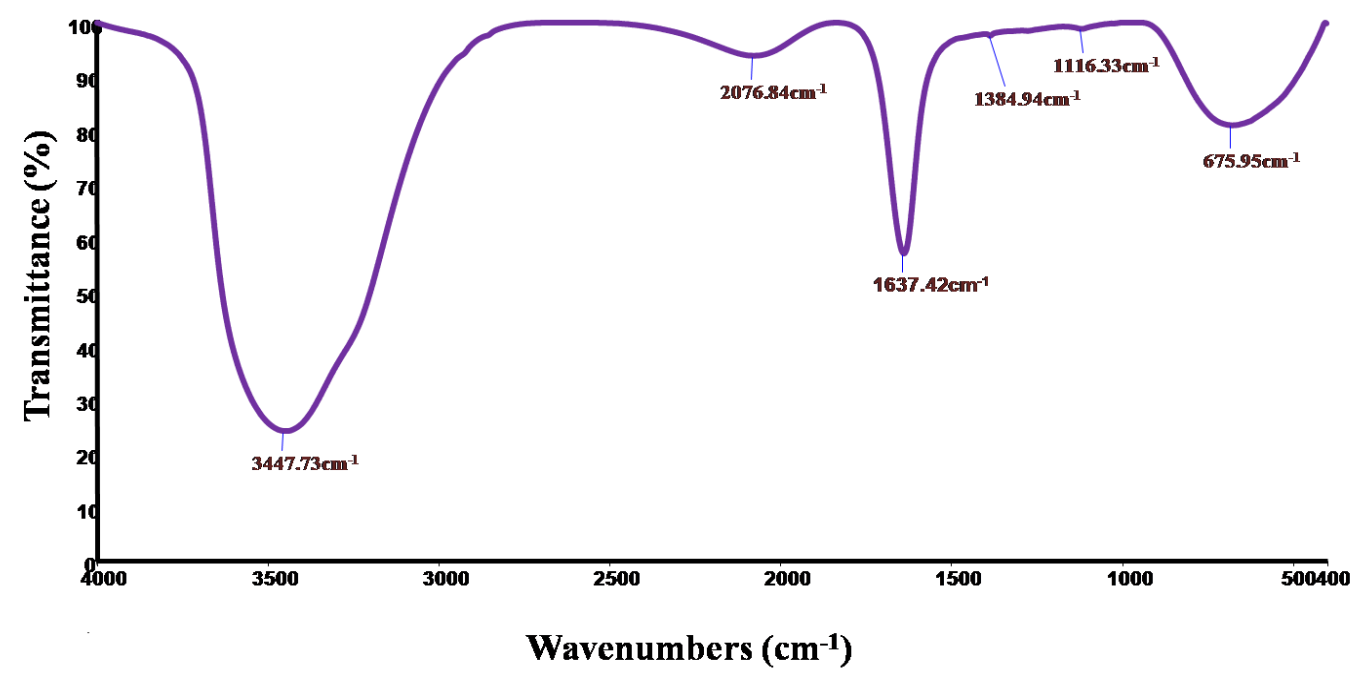

Figure 5. Fourier Transform Infrared Spectroscopy of a) Leaf Extract and b) MHL-CuO NPs.

The morphology and size of synthesized CuO NPs are analyzed by using FE-SEM. The shape of the particle is spherical. The size of the copper nanoparticle was found to be about 30-60 nm as shown in Figure 6a. and Figure 6b. The elemental composition of copper $(\mathrm{Cu})$ and oxide $(\mathrm{O})$ are highly present in EDAX analysis and a strong signal for Si which is due to glass wafer used as the substrate to prepare the thin film. The minor peaks elements correspond to the protein, which act as a capping over the copper oxide nanoparticles [19]. 

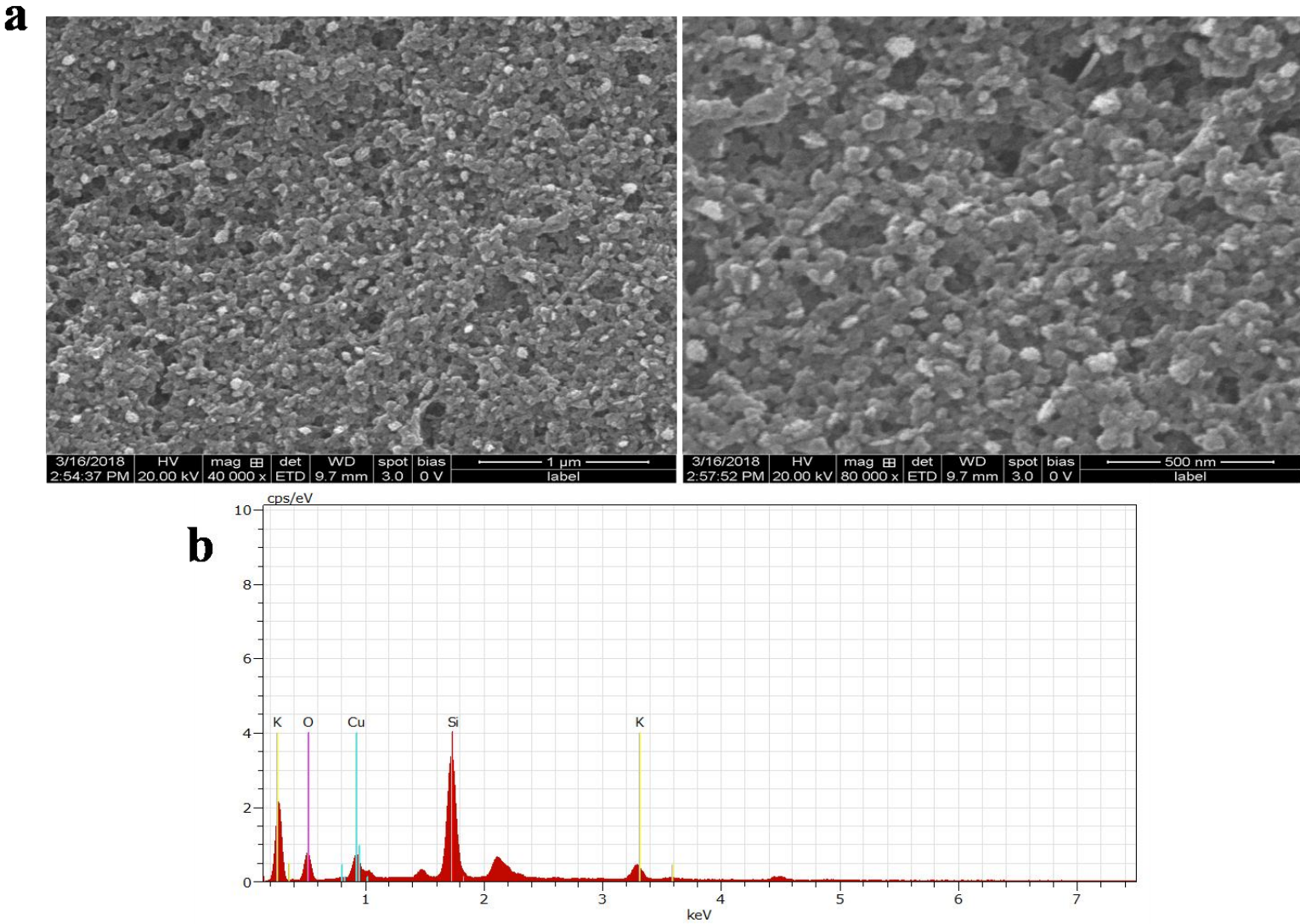

Figure 6.a)Field Emission Scanning Electron Microscopy (FE-SEM) image of MHL-CuO NPs and b) Energy Dispersive Spectroscopy (EDAX) spectrum of MHL-CuO NPs.

XRD analytic view small distinct peak at $32.523,38.873,46.323,48.773,51.323,58.373$ and 75.223 , which indexed the planes 110, 200, 112, 202, 112, 202 and 222 of the face-centered-cubic (FCC) structure of copper oxide nanoparticles (JCPDS-050661) as in Figure 7. The XRD pattern project that green synthesized CuO NPs are crystalline in nature [20].

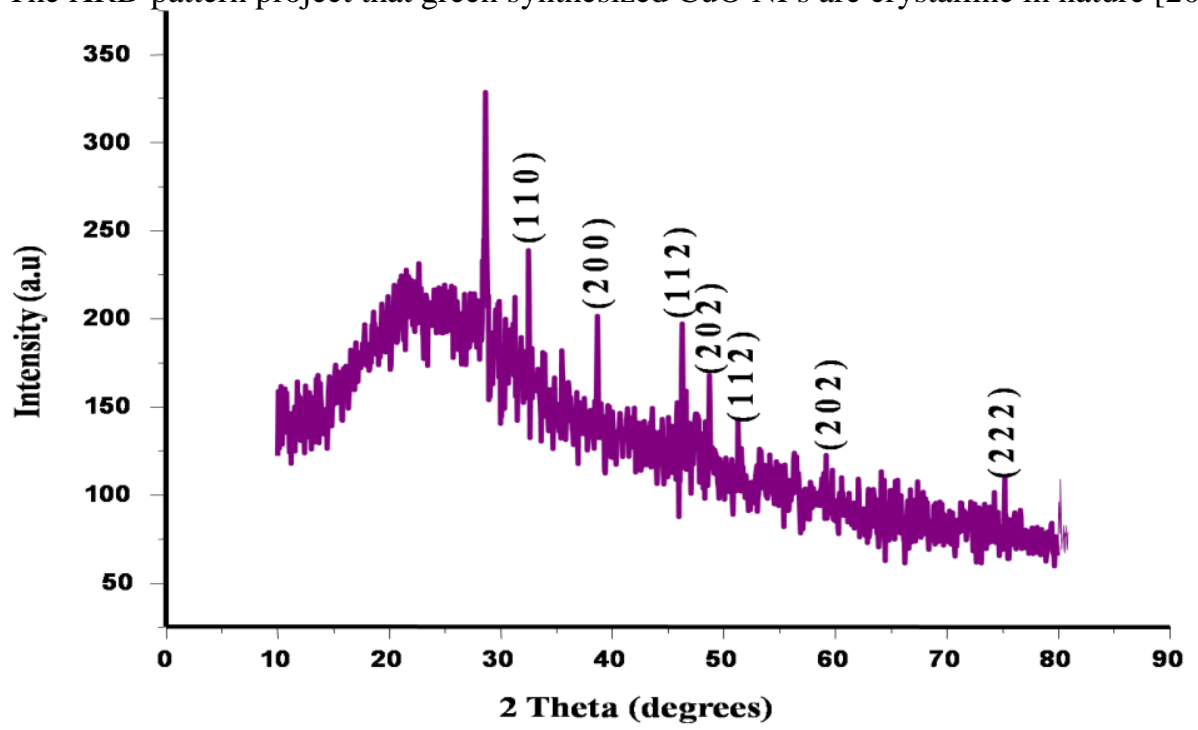

Figure 7. X-ray powder diffraction (XRD) of MHL-CuO NPs 
The particle size is analyzed by using DLS. The average particle size distribution was $343.1 \mathrm{~nm}$ shown in Figure 8a. Particle size is small in FE-SEM compared to DLS, since DLS is measured based on the hydrodynamic diameter of particles. The zeta potential value was found to be $-9.50 \mathrm{mV}$ shown in Figure $8 \mathrm{~b}$. The zeta potential value is high, which denote a strong repellent force within the particles and prevent aggregation $[21,22]$.

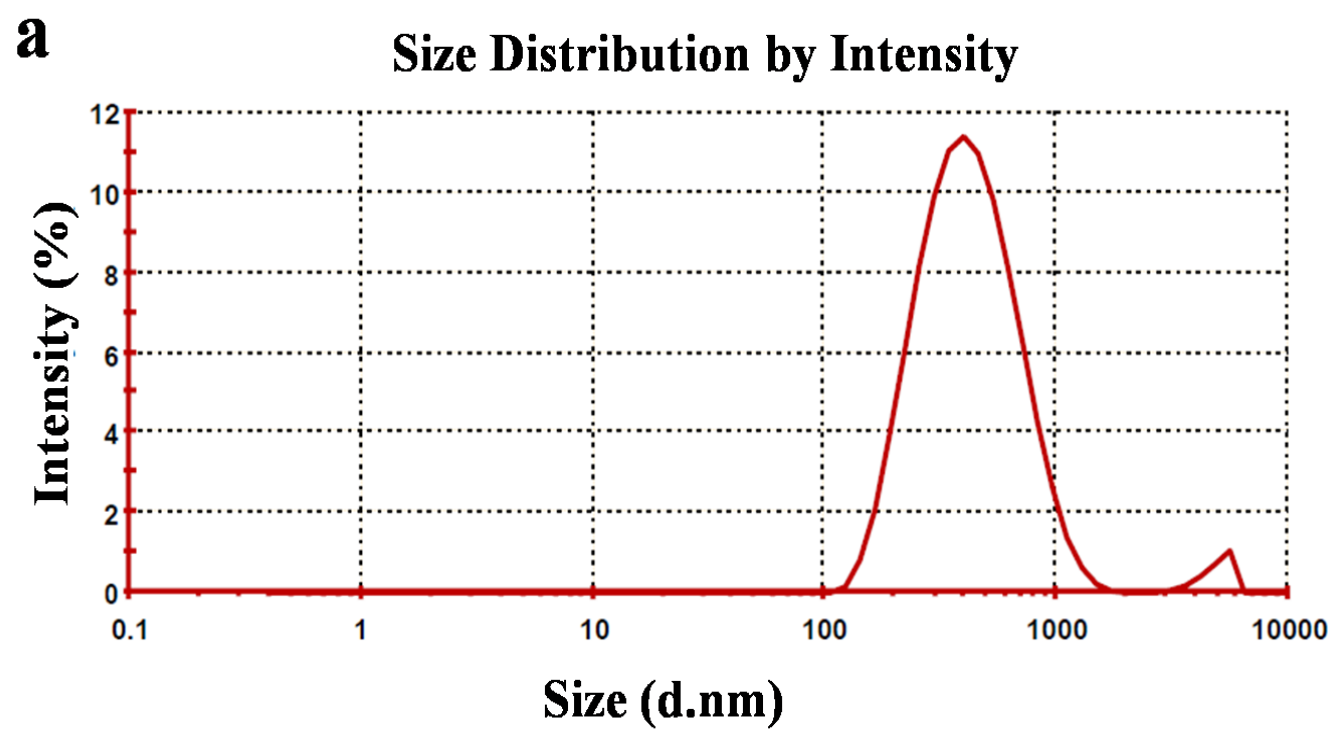

\section{b Zeta Potential Distribution}

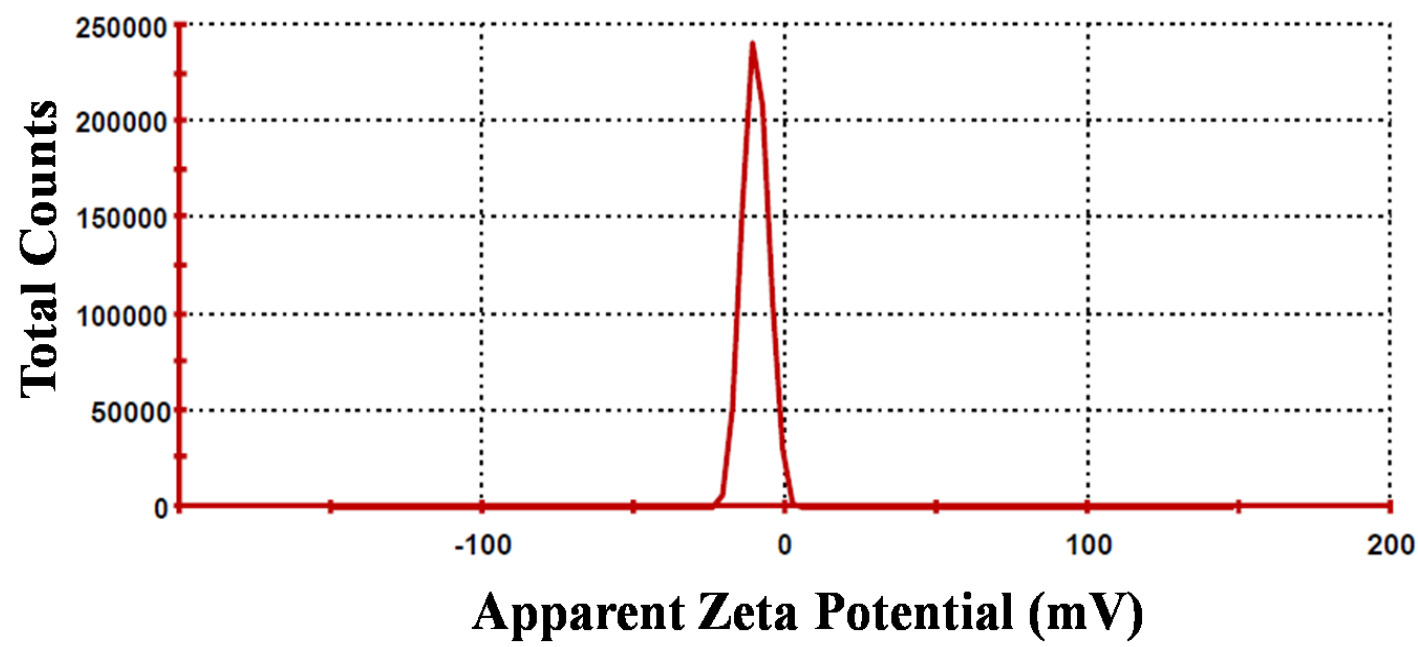

Figure 8. a)The hydrodynamic size of MHL-CuO NPs and b) Zeta potential of MHL-CuO NPs.

The MHL-CuO NPs was examined by TG/DTA to find the thermal stability. In TG curve, we observe weight lost from 3.8290 $\mathrm{mg}$ to $0.5565 \mathrm{mg}$ from room temperature to $900^{\circ} \mathrm{C}$ and the residue is $14.53 \%$ after $900^{\circ} \mathrm{C}$ it is constant there is no weight loss. The weight is been lost at six stages from room temperature to $104.27^{\circ} \mathrm{C}, 104.27^{\circ} \mathrm{C}$ to $201.08^{\circ} \mathrm{C}, 201.08$ to $387.64^{\circ} \mathrm{C}$ to $627.08^{\circ} \mathrm{C}, 627.08^{\circ}$ to $773.82^{\circ} \mathrm{C}, 773.82^{\circ} \mathrm{C}$ to $900^{\circ} \mathrm{C}$. The primary weight loss is due to the moisture content present in the nanoparticles. The major reduction, weight loss occurs at $201.08^{\circ} \mathrm{C}$ to $387.64^{\circ} \mathrm{C}$ and $387.64^{\circ} \mathrm{C}$ to $627.08^{\circ} \mathrm{C}$ this is due to decomposition of materials shown in Figure 9. 


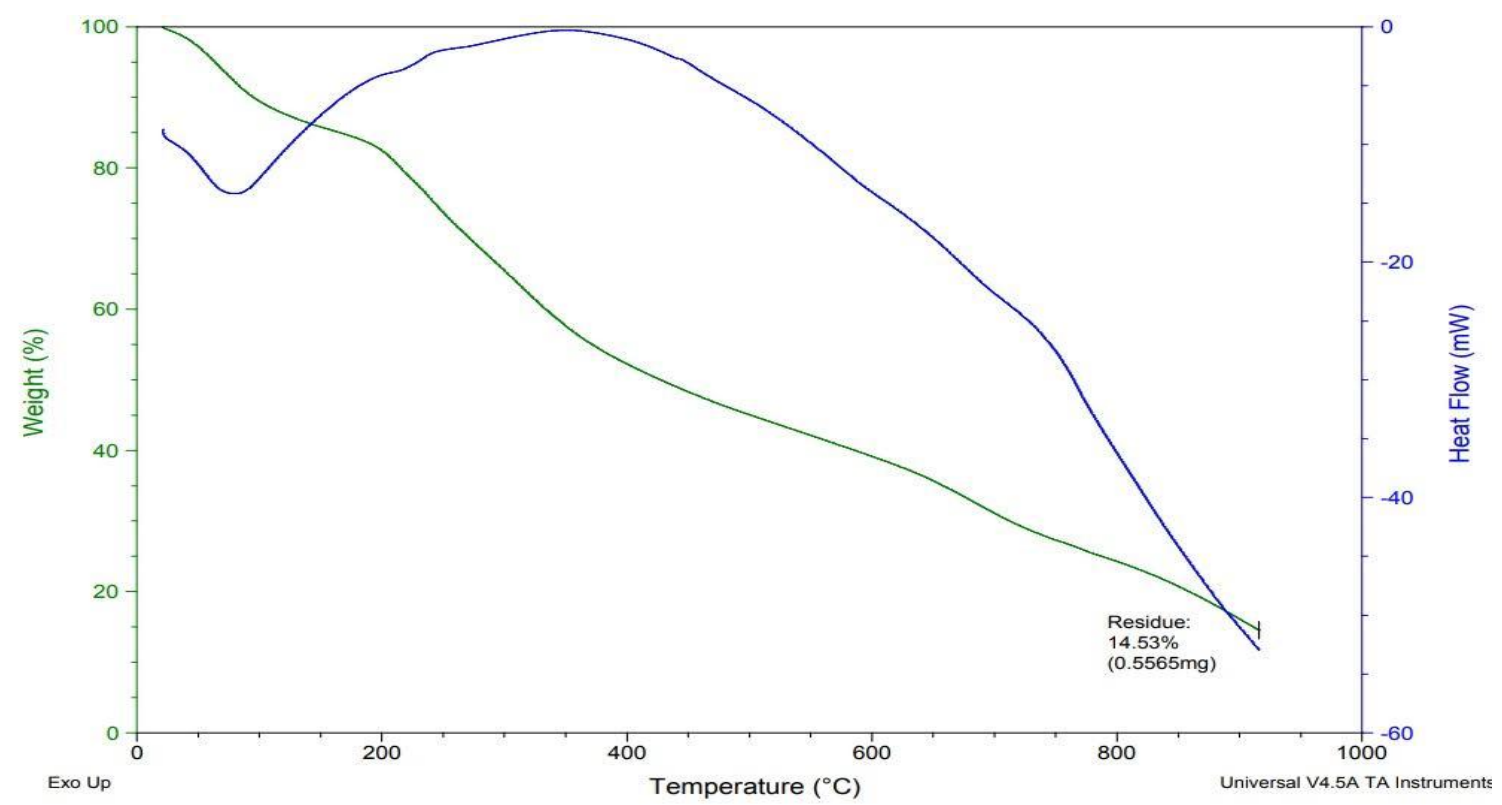

Figure 9. Thermogravimetry/Differential Thermal Analysis (TG/DTA) of MHL-CuO NPs.

The DTA thermograms reveals an endothermic peak at $65^{\circ} \mathrm{C}$. The exothermic peak at $240^{\circ} \mathrm{C}$ shows the decomposition of copper nanoparticles and another exothermic peak shown at $345^{\circ} \mathrm{C}$ depict the stability of the material. The nanoparticles can be examined by DTA for thermal decomposition and crystallization of the material [23]. In the DSC curve, we observe four endothermic peak at $61.7^{\circ} \mathrm{C}, 84.9^{\circ} \mathrm{C}, 125^{\circ} \mathrm{C}, 220^{\circ} \mathrm{C}$ and small other bumps. There is also an exothermic peak at $76^{\circ} \mathrm{C}, 120^{\circ} \mathrm{C}, 170^{\circ} \mathrm{C}, 210^{\circ} \mathrm{C}$ and small other bumps. They show clearly that the particles are stable up to $250^{\circ} \mathrm{C}$. The peaks are due to degradation of molecules present in the materials and is shown in Figure 10.

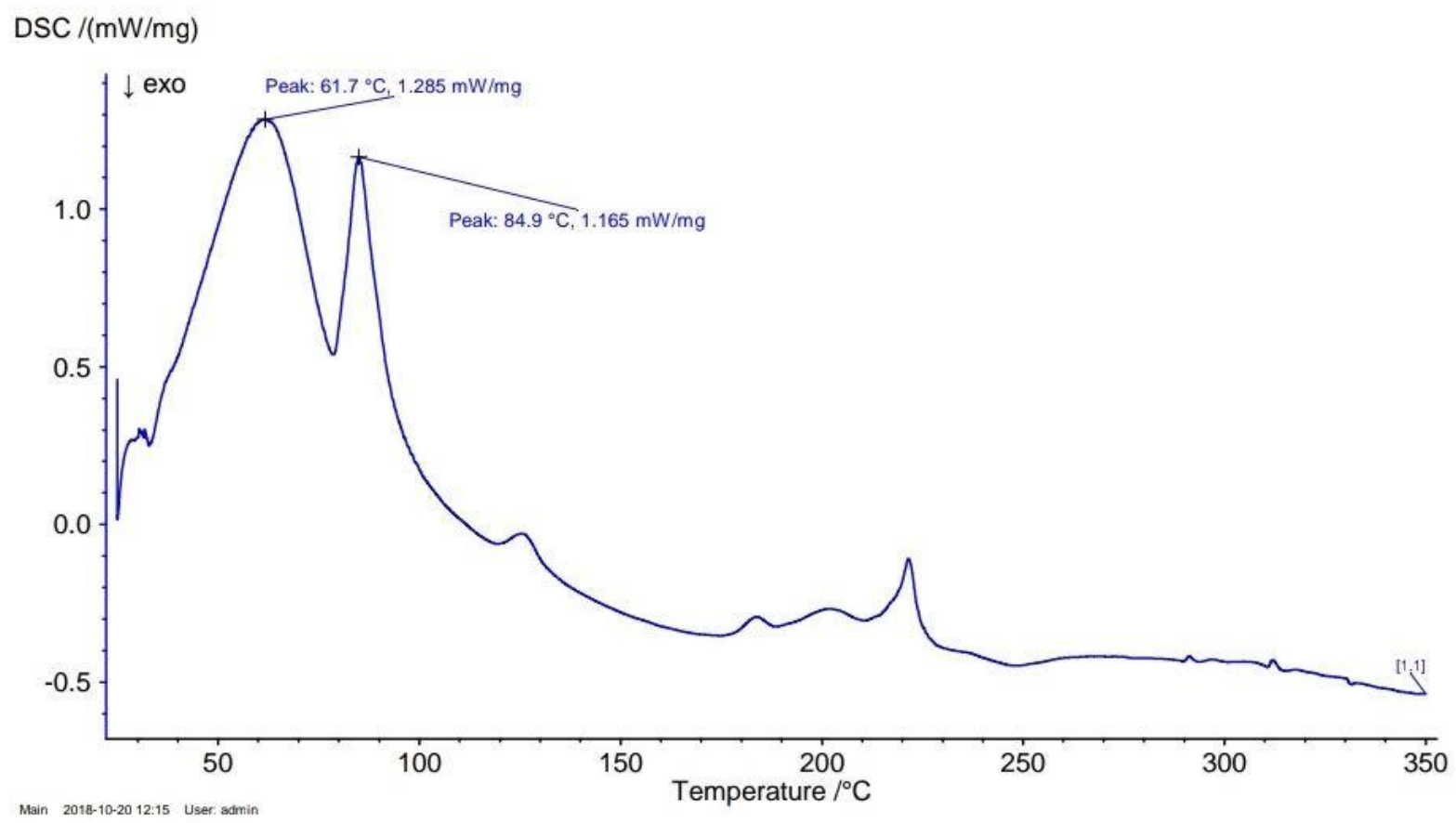

Figure 10. Differential scanning calorimetry (DSC) of MHL-CuO NPs. 


\subsection{Antimicrobial evaluation}

The antibacterial activity of various samples such as MHL-CuO NPs, Manilkara hexandra leaf extract, copper sulfate (5mM) and Standard was tested against pathogens by disk diffusion method. The CuO NPs showed growth inhibitory action against Escherichia coli $(8 \mathrm{~mm})$ and Staphylococcus aureus $(7 \mathrm{~mm})$. The Manilkara hexandra leaf extract exhibited the antibacterial activity all the four bacteria, but was more susceptible against Escherichia coli (10 mm), Pseudomonas aeruginosa (7 mm). However, the leaf extract and copper oxide nanoparticles showed better inhibitory actions against bacteria. Copper sulfate $(5 \mathrm{mM})$ shows no zone of inhibition. Amoxicillin is used as the standard to find the range of activity. The antifungal susceptibility test of the different samples such as MHL-CuO NPs, Manilkara hexandra leaf extract, copper sulfate (5mM) and the standard was tested against the test organisms. The MHL-CuO NPs were the most effective and the highest activity was seen against Aspergillus niger (9 mm zone of inhibition), followed by the highest activity against Aspergillus flavus (6 mm zone of inhibition). The Manilkara hexandra leaf extract showed the activity against Aspergillus niger (7 mm zone of inhibition) shown in Table 1. and Figure 11. Fluconazole was used as the standard to analyze testing organisms. Antimicrobial assays are represented in the bar chart, it is shown in Figure 12.

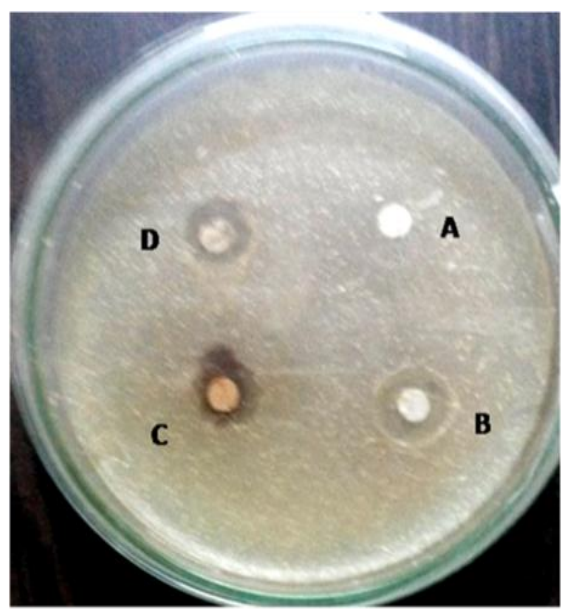

Staphylococcus aureus

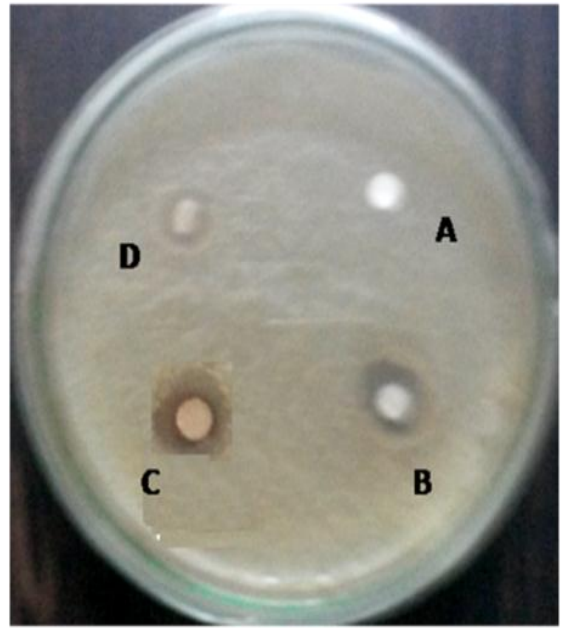

Pseudomonas aeruginosa

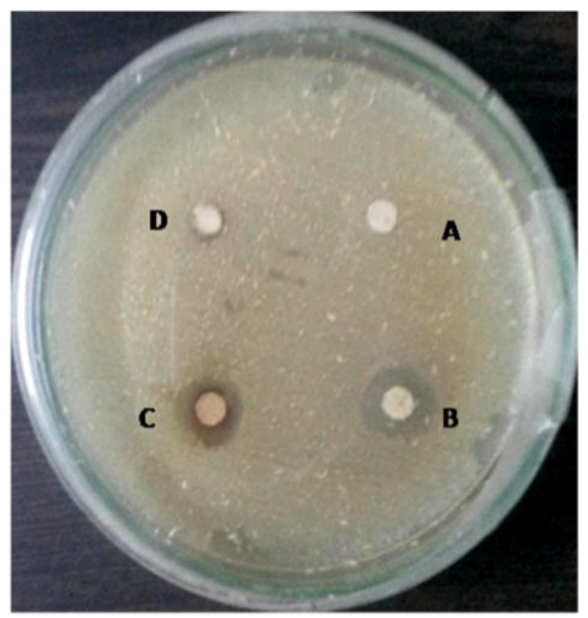

Bacillus subtilis

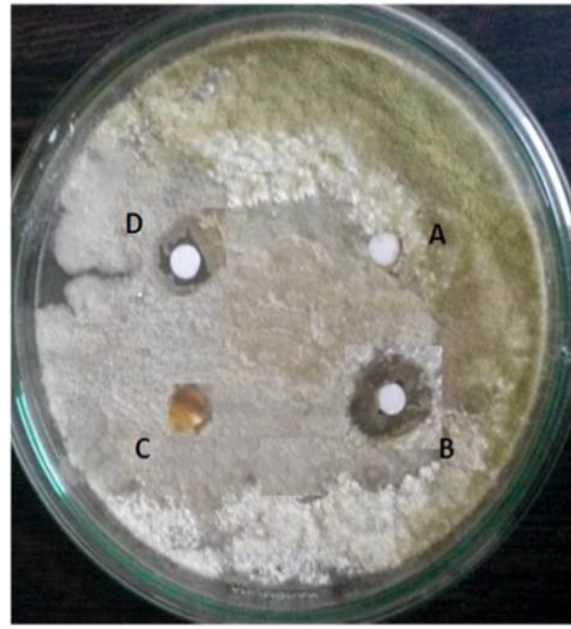

Aspergillus flavus

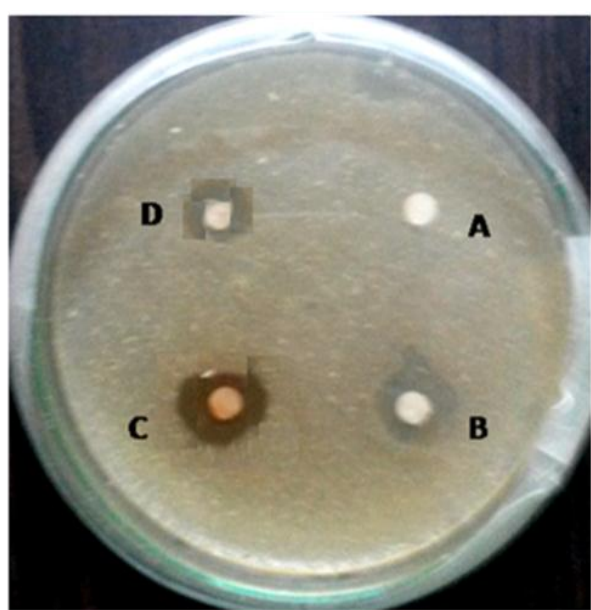

Escherichia coli

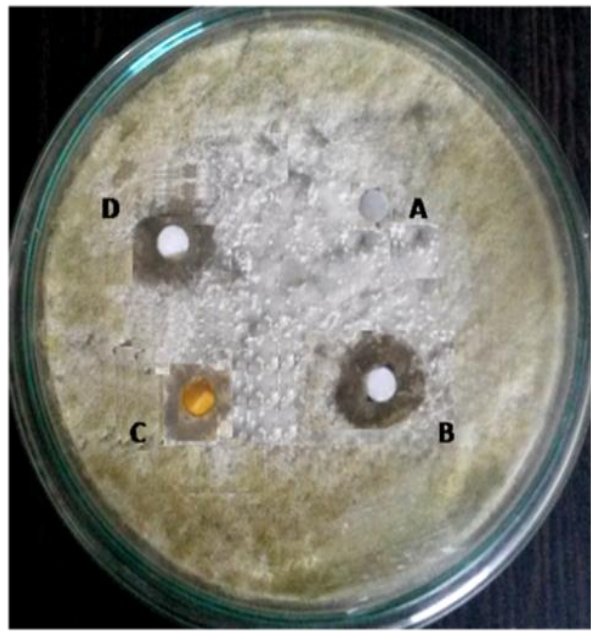

Aspergillus niger

Figure 11.Various Antibacterial and Antifungal strains. Zone of Inhibition of MHL-CuO NPs, Leaf Extract, $\mathrm{CuSO}_{4}$ and Standard. 


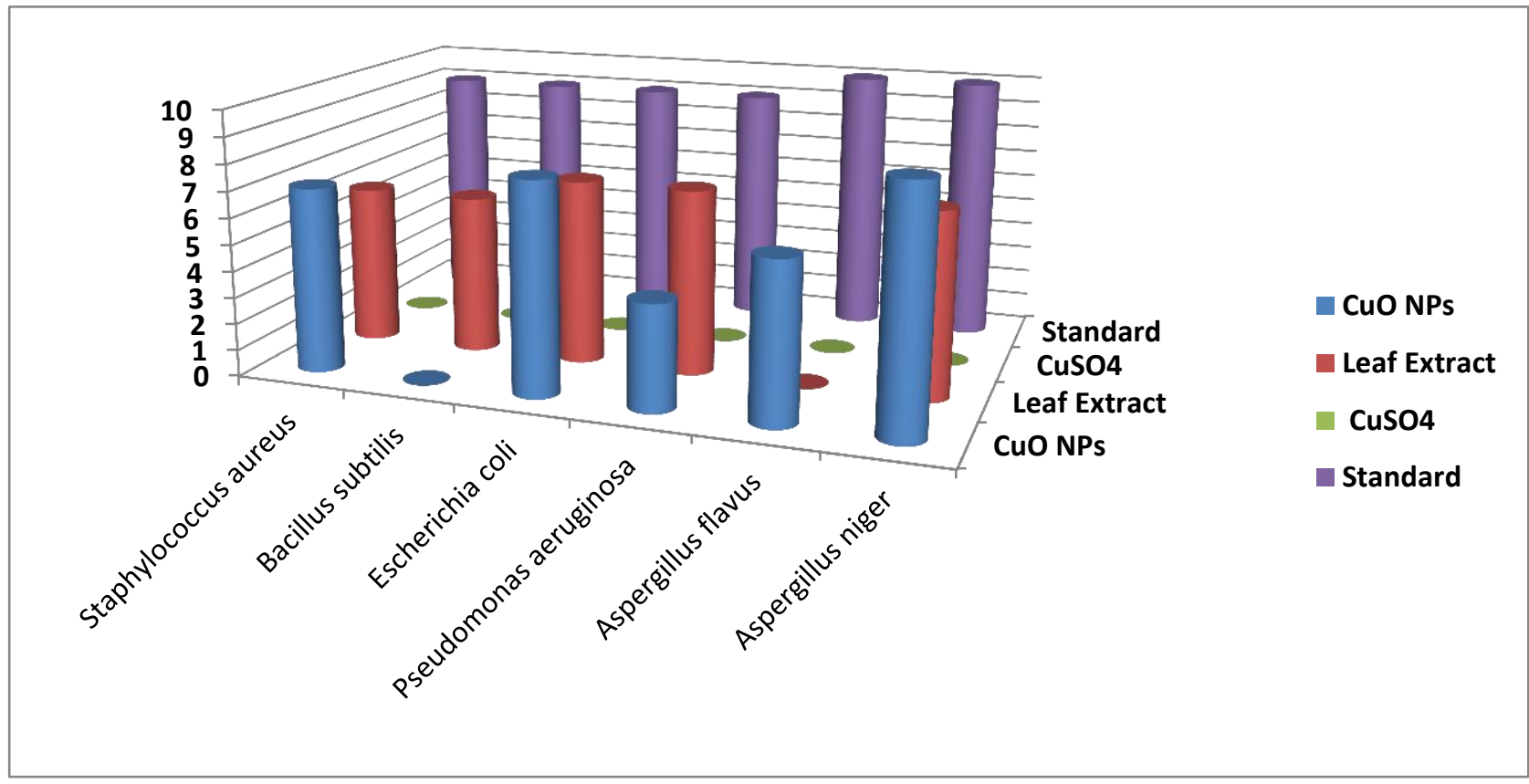

Figure 12. Zone of inhibition of $\mathrm{CuO}$ NPs, Leaf extract, $\mathrm{CuSO}_{4}$, Standard with different microbes is shown in bar chart.

Table 1. Zone of Inhibition of $\mathrm{CuO}$ NPs, Leaf Extract, $\mathrm{CuSO}_{4}$, and standard against various microbes.

\begin{tabular}{|c|c|c|c|c|c|}
\hline \multirow{3}{*}{ S.No } & \multirow{3}{*}{ Name of the organism } & \multicolumn{4}{|c|}{ Zone of inhibition in $\mathbf{m m}$} \\
\hline & & \multicolumn{4}{|c|}{$\begin{array}{c}\text { Concentrations } \\
(10 \mu \mathrm{l} / \mathrm{ml})\end{array}$} \\
\hline & & $\begin{array}{l}\text { CuO NPs } \\
\text { (D) }\end{array}$ & $\begin{array}{c}\text { Leaf } \\
\text { Extract } \\
(\mathbf{C})\end{array}$ & $\begin{array}{l}\mathrm{CuSO}_{4} \\
\text { (A) }\end{array}$ & $\begin{array}{c}\text { Standard (B) } \\
\text { Amoxicillin / } \\
\text { Fluconazole }\end{array}$ \\
\hline 1. & Staphylococcus aureus (MTCC 25923) & 7 & 6 & 0 & 9 \\
\hline 2. & Bacillus subtilis (MTCC 2451) & 0 & 6 & 0 & 9 \\
\hline 3. & Escherichia coli (MTCC 25922) & 8 & 7 & 0 & 9 \\
\hline 4. & Pseudomonas aeruginosa (MTCC 27853) & 4 & 7 & 0 & 9 \\
\hline 5. & Aspergillus flavus (MTCC-3396) & 6 & 0 & 0 & 10 \\
\hline 6. & Aspergillus niger (MTCC-227) & 9 & 7 & 0 & 10 \\
\hline
\end{tabular}

\subsection{Antioxidant (DPPH method in-vitro)}

The antioxidant activity is examined using the DPPH method for various concentrations of copper oxide nanoparticles from 20 $\mu \mathrm{g} / \mathrm{ml}$ to $100 \mu \mathrm{g} / \mathrm{ml}$. They are alternatively compared with standard (ascorbic acid). Here MHL-CuO NPs show a good antioxidant property but low compared with the standard. But, MHL-CuO NPs are non toxic and has no side effect. The ascorbic acid (standard) causes side effect. They are compared and the IC50 value is calculated as in Figure 13 and Table 2. 


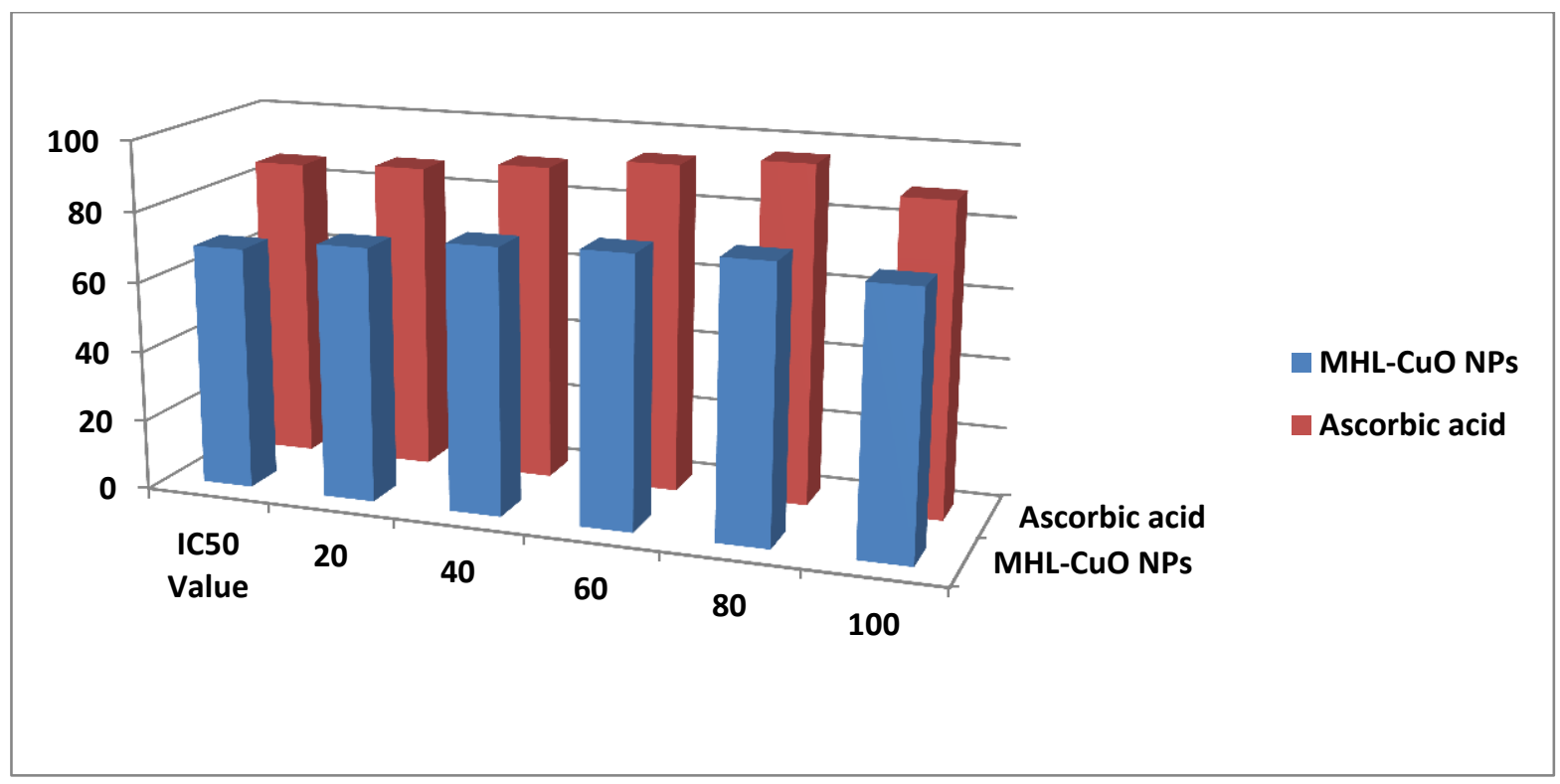

Figure 13. Anti-oxidant activity (DPPH method) represented in bar chart.

Table 2. free radical scavenging activities of MHL-CuO NPs and Standard.

\begin{tabular}{|c|c|c|}
\hline $\begin{array}{c}\text { Concentration of } \\
\text { sample }(\boldsymbol{\mu g} / \mathbf{m l})\end{array}$ & MHL-CuO NPs & Ascorbic acid \\
\hline 20 & 69.17 & 86.35 \\
\hline 40 & 72.43 & 87.56 \\
\hline 60 & 75.62 & 90.34 \\
\hline 80 & 76.82 & 93.57 \\
\hline 100 & 77.70 & 96.23 \\
\hline IC50 Value & $\mathbf{7 4 . 2 3}$ & $\mathbf{8 8 . 9 0}$ \\
\hline
\end{tabular}

\section{CONCLUSION}

The present bio-synthetic method is an easy, eco-friendly, economical and rapid form of synthesis at room temperature. To synthesize $\mathrm{CuO}$ NPs, there is no need of an external capping agent. This method produced spherical, a polydispersed form of nanoparticles. It is well separated from each other and no aggregation was observed. Based on the above experiment we observe that this method can also be indulged in a large industrial scale of fabrication of nanomaterials. The antimicrobial properties of synthesized $\mathrm{CuO}$ NPs having the size range from $30 \mathrm{~nm}$ to $60 \mathrm{~nm}$ were effective against pathogens. It also show good antioxidant potential. This $\mathrm{CuO}$ NPs can be used for the improvement of agriculture, food safety product and for drug delivery system.

\section{REFERENCES}

[1]. A. Nostro, M.P. Germano, V. Dangelo, A. Marino, M.A. Cannatelli, "Extraction methods and bioautography for evaluation of medicinal plant antimicrobial activity”, Letters in Applied Microbiology,Vol. 30, Issue.,5, pp. 379-384, 2000.

[2]. T.N.V.K.V Prasad, Elumalai E.K, "Biofabrication of Ag nanoparticles using M. oleifera leaf extract and their antimicrobial activity", Asian Pacific Journal of Tropical Biomedicine, Vol. 1, Issue.,6, pp. 439-442, 2011.

[3]. B.A. Makwana, D.J. Vyas, K.D. Bhatt, V.K. Jain, Y.K. Agrawal, "Highly stable antibacterial silver nanoparticles as selective fluorescent sensor for Fe3p ions", Spectrochimica Acta Part A: Molecular and Biomolecular Spectroscopy, Vol. 134, pp. 73-80, 2015. 
[4]. V. Kumar , S.K. Yadav, "Plant-mediated synthesis of silver and gold nanoparticles and their applications", Journal of Chemical Technology \& Biotechnology, Vol. 84, Issue.,2,pp.151-157,2009.

[5]. A.K. Chatterjee, R.K. Sarkar, A.P. Chattopadhyay, P. Aich, R. Chakraborty, T. Basu, "A simple robust method for synthesis of metallic copper nanoparticles of high antibacterial potency against E. coli”, Nanotechnology, Vol. 23, pp.1-11, 2012.

[6]. B. Ajitha, Y.A.K. Reddy, P.S. Reddy, Y. Suneetha, H.J. Jeon, C.W. Ahn, "Instant biosynthesis of silver nanoparticles using Lawsonia inermis leaf extract: Innate catalytic, antimicrobial and antioxidant activities", Journal of Molecular Liquids, Vol. 219,pp. 474-481,2016.

[7]. K. Sneha, M. Sathishkumar, S. Y. Lee, M. A. Bae, Y-S. Yun, "Biosynthesis of Au nanoparticles using cumin seed powder extract”, Journal of Nanoscience and Nanotechnology, Vol.11, Issue.,2,pp. 1811- 1814,2011.

[8]. P. Reddy Prasad, S. Kanchi, E.B. Naidoo, "In-vitro evaluation of copper nanoparticles cytotoxicity on prostate cancer cell lines and their antioxidant, sensing and catalytic activity: One-pot green approach”, Journal of Photochemistry and Photobiology B: Biology, Vol. 161, pp. 375-382,2016.

[9]. J. Suarez-Cerda, H. Espinoza-Gomez, G. Alonso-Nunez, I.A. Rivero, Y. Gochi-Ponce, L.Z. Flores-Lopez, "A green synthesis of copper nanoparticles using native cyclodextrins as stabilizing agents", Journal of Saudi Chemical Society, Vol. 21, Issue.,3,pp. 341-348,2017.

[10]. M.S. Niasari, F. Davar, "Synthesis of copper and copper (I) oxide nanoparticles by thermal decomposition of a new precursor". Materials Letters, Vol. 63,Issue.,3-4, pp. 441- 443,2009.

[11]. G. Ren, D. Hu, E.W.C. Cheng, M.A. Vargas-Reus, P. Reip, R.P. Allaker, "Characterisation of copper oxide nanoparticles for antimicrobial applications". International Journal of Antimicrobial Agents, Vol. 33, Issue.,6, pp. 587-590,2009.

[12]. R. Dastjerdi, M. Montazer, "A review on the application of inorganic nanostructured materials in the modification of textiles: Focus on antimicrobial properties”. Colloids and Surfaces B: Biointerfaces, Vol. 79, Issue.,1, pp.5-18,2010.

[13]. S Irudaya Monisha, G Dayana Jeyaleela,A.Anitha Immaculate and J Rosaline Vimala, "Comparative studies on yield and the phytochemical appraisal(Quality and Quantity) of Manilkara hexandra(Roxb) Dubard using leaf, stem, and bark". Journal of Pharmacognosy and Phytochemistry. Vol.6, Issue.,4,pp. 2052-2058,2017.

[14]. J.B. Harborne, “Textbook of phytochemical methods", 1st ed., Chapman and Hall, London, 1973.

[15]. Bhattacharya D, Rajinder G, "Nanotechnology and potential of microorganisms". Critical Reviews in Biotechnology. Vol. 25, Issue.,4, pp.199204,2005.

[16]. Mohamed S. Abdel-Aziz, Mohamed S. Shaheen , Aziza A. El-Nekeety , Mosaad A. Abdel-Wahhab. 2014. “Antioxidant and antibacterial activity of silver nanoparticles biosynthesized using Chenopodium murale leaf extract”. Journal of Saudi Chemical Society. Vol.18, Issue.,4, pp. 356-363,2014.

[17]. A. Azam, A.S. Ahmed, M. Oves, M.S. Khan, A. Memic, "Size-dependent antimicrobial properties of CuO nanoparticles against Gram-positive and -negative bacterial strains". International Journal of Nanomedicine. Vol. 7, pp. 3527-3535, 2012.

[18]. P. Mulvaney, "Surface Plasmon Spectroscopy of Nanosized Metal Particles". Langmuir. Vol.12, Issue.,3, pp. 788-800, 1996.

[19]. N. Ahmad, S. Sharma, V.N. Singh, S.F. Shamsi, A. Fatma, B.R. Mehta, "Biosynthesis of Silver Nanoparticles from Desmodium triflorum: A Novel Approach Towards Weed Utilization”. Biotechnology Research International. Vol. 2011, Article ID 454090, pp. 1-8, 2011.

[20]. A.S. Ethiraj, D.J. Kang, "Synthesis and characterization of CuO nanowires by a simple wet chemical method". Nanoscale Research Letters. Vol. 7, Issue., 70, pp. 1-5, 2012.

[21]. L. Lin, P. Qiu, X. Cao, L. Jin, "Colloidal silver nanoparticles modified electrode and its application to the electroanalysis of Cytochrome c". Electrochimica Acta. Vol. 53, Isssue., 16, pp. 5368-5372, 2008.

[22]. R. Sankar, A. Karthik, A. Prabu, S. Karthik, K.S. Shivashangari, V. Ravikumar, "Origanum vulgare mediated biosynthesis of silver nanoparticles for its antibacterial and anticancer activity". Colloids and Surfaces B: Biointerfaces. Vol. 108, pp. 80-84, 2013.

[23]. Mohd Abdul Majeed Khan, Sushil Kumar, Maqusood Ahamed, Salman A Alrokayan and Mohammad Saleh AlSalhi. 2011. "Structural and thermal studies of silver nanoparticles and electrical transport study of their thin films". Nanoscale Research Letters. Vol. 6:434,pp.1-8,2011.

\section{Author Profile}

Mr. A . Antony Lawrence persued B.Sc (Physics) in 2005 in St.Joseph College, Cuddalore,Tamil nadu and finished his B.Ed (Education) in 2012, Kamala College of Education next did M. Sc. (Physics) in 2014 from Annamalai University, Chidambaram,Tamil nadu, India. After persued M.Ed (Eduaction) in 2015 in National College of Education,Neyveli,Tamil nadu and received M.Phil (Physics) in 2016 from Thanthai Hans Roever college,Perambalur, Tamil nadu. Presently doing his P.hD in Physics, Government Arts College (Affiliated to Bharathidasan University), Trichy, Tamil Nadu-620022.

e-mail: bonjour.aal@gmail.com Mobile:+91-8190918082.

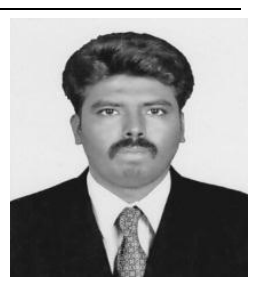

Mr. J. Thomas Joseph Prakash is an Assistant Professor of Physics in Government Arts College,Trichy. He is a passionate academician, research supervisor in physics, with more than 22 years over 64 articles in national and international referred journals in the area of material science. He produced 12 M.Phil./8 Ph.D., Research Scholars in the field of Physics, and 25 master degree students finished their research work under his guidance.

e-mail: armyjpr1@yahoo.co.in Mobile: +91-9842470521.

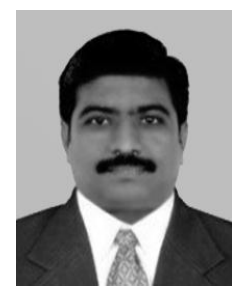

